\title{
Prevalence of ocular signs and subclinical vitamin A deficiency and its determinants among rural pre-school children in India
}

\author{
Avula Laxmaiah ${ }^{1, *}$, Madhavan K Nair ${ }^{2}$, Nimmathota Arlappa ${ }^{1}$, Pullakhandam Raghu², \\ Nagalla Balakrishna ${ }^{3}$, Kodavanti Mallikharjuna Rao ${ }^{1}$, Chitty Galreddy ${ }^{1}$, \\ Sharad Kumar ${ }^{1}$, Manachala Ravindranath ${ }^{1}$, Varaganti Vikas Rao ${ }^{2}$ and \\ Ginnela NV Brahmam ${ }^{1}$ \\ 'Division of Community Studies, National Institute of Nutrition (Indian Council of Medical Research), \\ Jamai-Osmania, Hyderabad 500 007, India: ${ }^{2}$ Micronutrient Research, Biophysics Division, National Institute \\ of Nutrition, Indian Council of Medical Research, Hyderabad, India: ${ }^{3}$ Division of Biostatistics, National Institute \\ of Nutrition (Indian Council of Medical Research), Hyderabad, India
}

Submitted 25 December 2010: Accepted 14 July 2011: First published online 2 September 2011

\begin{abstract}
Objective: To assess the magnitude and determinants of vitamin A deficiency (VAD) and coverage of vitamin A supplementation (VAS) among pre-school children. Design: A community-based cross-sectional study was carried out by adopting a multistage, stratified, random sampling procedure.

Setting: Rural areas of eight states in India.

Subjects: Pre-school children and their mothers were covered.

Results: A total of 71591 pre-school children were clinically examined for ocular signs of VAD. Serum retinol concentrations in dried blood spots were assessed in a sub-sample of 3954 children using HPLC. The prevalence of Bitot spots was $0 \cdot 8 \%$. The total ocular signs were significantly higher $(P<0 \cdot 001)$ among boys $(2 \cdot 6 \%)$ compared with girls $(1.9 \%)$ and in older children (3-4 years) compared $(P<0 \cdot 001)$ with younger (1-2 years), and were also high in children of labourers, scheduled castes and illiterate mothers. The odds of having Bitot spots was highest in children of scheduled caste (OR $=3 \cdot 8 ; 95 \%$ CI $2 \cdot 9,5 \cdot 0)$, labourers $(\mathrm{OR}=2 \cdot 9 ; 95 \% \mathrm{CI} 2 \cdot 1,3 \cdot 9)$, illiterate mothers $(\mathrm{OR}=2 \cdot 7 ; 95 \% \mathrm{CI} 2 \cdot 2,2 \cdot 3)$ and households without a sanitary latrine $(\mathrm{OR}=5 \cdot 9 ; 95 \% \mathrm{CI} 4 \cdot 0,8 \cdot 7)$. Subclinical VAD (serum retinol level $<20 \mu \mathrm{g} / \mathrm{dl}$ ) was observed in $62 \%$ of children. This was also relatively high among scheduled caste and scheduled tribe children. The rate of coverage of VAS was $58 \%$.

Conclusions: The study revealed that VAD is a major nutritional problem and coverage of VAS was poor. The important determinants of VAD were illiteracy, low socio-economic status, occupation and poor sanitation. Strengthening the existing VAS programme and focused attention on dietary diversification are essential for prevention of VAD.
\end{abstract}

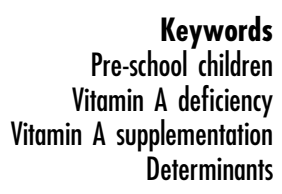

Vitamin A deficiency (VAD) is the leading cause of paediatric blindness and a major determinant of severe infections and mortality among children in the developing world. There are an estimated 130 million pre-school children with subclinical VAD defined by serum retinol concentration of $<20 \mu \mathrm{g} / \mathrm{dl}$ or $<0 \cdot 7 \mu \mathrm{mol} / \mathrm{l}^{(1)}$. The ocular signs of VAD include night blindness, conjunctival xerosis, Bitot spots, corneal ulceration, keratomalacia and total blindness. Several studies have revealed that there is a positive association between VAD and increased respiratory infections ${ }^{(2,3)}$, diarrhoea, measles and childhood mortality $^{(4-9)}$. VAD compromises the immune system in $40 \%$ of children in the developing world and contributes to one million deaths of young children each year ${ }^{(10,11)}$.
VAD is the most common cause of preventable blindness and is estimated to account for $2 \%$ of total blindness in India ${ }^{(12,13)}$. According to WHO, about 60000 children go blind each year due to VAD in India ${ }^{(14,15)}$. Considering the implications of VAD among children, the Government of India launched a massive-dose vitamin A supplementation (VAS) programme in 1970. The programme is sponsored by the Ministry of Health and Family Welfare, Government of India and the beneficiaries include children in the age group of 9-59 months. Administration of the first two doses of VAS is linked to routine immunisation to improve its coverage ${ }^{(16)}$ following the guidelines of WHO. Under the programme, the first vitamin A dose of $30000 \mu \mathrm{g}$ is administered along with the measles 
vaccination (9 months) while the second dose of $60000 \mu \mathrm{g}$ is given with the booster dose of DPT (diphtheria, pertussis and tetanus) and polio (15 months). Subsequent doses are given twice annually up to the age of 5 years. The programme is being implemented round the year.

Despite the existence of the VAS programme for more than three decades, VAD still persists in many districts and states of India ${ }^{(12)}$ and this leads to a national debate on the contribution of this programme to alleviating VAD. However, a significant decline has been observed in the prevalence of severe ocular forms of VAD such as corneal ulcer and keratomalacia, while Bitot spots continues to be a major public health problem among pre-school children $^{(17-22)}$.

There are no large-scale community-based studies on VAD at a national level, except sporadic studies on ocular signs or subclinical VAD, in India. Such data are essential to design various strategies for VAD prevention and control. Therefore, the present study was carried out by the National Nutrition Monitoring Bureau (NNMB) among rural pre-school children in eight states during 2002-2005. Part of the data of the study pertaining to the states of Maharashtra, West Bengal and Madhya Pradesh has been published elsewhere ${ }^{(23-26)}$. An attempt has been made in the present paper to arrive at the national estimates on the prevalence and determinants of VAD.

\section{Materials and methods}

\section{Sampling design}

A community-based cross-sectional study was carried out among rural pre-school children by adopting a multistage, stratified, random sampling procedure in eight states, i.e. Andhra Pradesh, Karnataka, Kerala, Madhya Pradesh, Maharashtra, Orissa, Tamil Nadu and West Bengal, during 2002-2005 (Fig. 1). The NNMB has been carrying out national surveys periodically on 'diet and nutrition' in ten major states since 1975 . The NNMB studies utilise robust sampling procedures such that there is a probability of about $75 \%$ of India's population being included in the study ${ }^{(19)}$.

\section{Computation of sample size}

Ocular signs. A sample size of 8777 pre-school children was arrived at for each state for determining clinical VAD based on the prevalence of Bitot spots of $1 \%{ }^{(18)}$ with $95 \%$ confidence interval and a relative precision of $20 \%$.

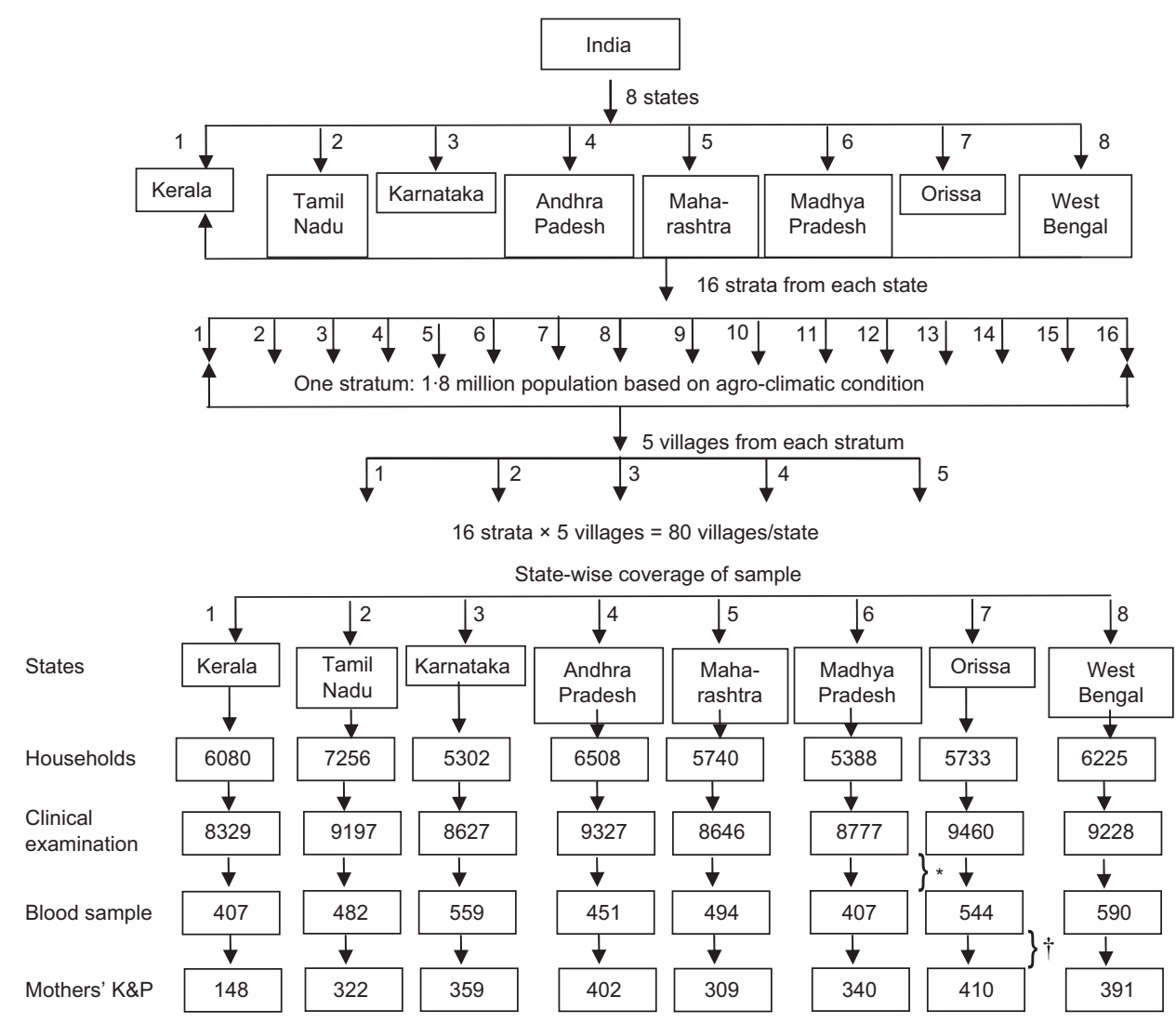

Fig. 1 Flowchart of the sampling procedure of the community-based cross-sectional study carried out to determine the magnitude and determinants of vitamin A deficiency and coverage of vitamin A supplementation among Indian pre-school children. ${ }^{*} B l o o d$ sample was obtained from every 20th child seen for clinical examination; †knowledge and practices (K\&P) were assessed for every 25th mother. The coverage in Gujarat and Uttar Pradesh was $<50 \%$ of the target sample and therefore the data of these two states were not included in the present analysis 
A design effect of 2 was considered for national-level estimation of sample size.

Serum retinol concentrations. No design effect was considered for estimation of sample size for the prevalence of low serum retinol concentrations. A sample size of 400 was considered for each state based on the following parameters. We assumed $50 \%$ prevalence of low serum retinol concentrations $<20 \mu \mathrm{g} / \mathrm{dl}^{(4)}$ with $95 \%$ confidence interval and a relative precision of $10 \%$.

\section{Selection of strata}

Each state was divided into twenty to fifty strata based on agro-climatic variables and size of the population in the state ${ }^{(27)}$; one district or part of the district of population 1.8 million was considered as one stratum. For the present study, a total of sixteen strata were randomly selected from each state.

\section{Selection of villages}

From each stratum, five villages were randomly selected. Thus, a total (sixteen strata $\times$ five villages) of eighty villages were selected in each state (Fig. 1). The coverage in two (Gujarat and Uttar Pradesh) out of the ten states was $<50 \%$ of target samples and, therefore, the data were not included in the present analysis.

\section{Selection of subjects}

Each selected village was divided into five geographical areas based on natural lanes or streets to give a spatial representation of the village. Households belonging to economically weaker sections of society such as scheduled caste/scheduled tribe (SC/ST) communities, who generally live in a group, constituted one of the five areas. All the households including pre-school children in each geographical area were enumerated. The required number of children to be covered from each of the selected villages was determined on the basis of probability proportional to population size (PPS) of the village. The required number of children was covered randomly from all five geographical areas of the selected village. The first household with a pre-school child was selected randomly and the required number of children was covered contiguously from each geographical area. All the mothers of children from whom the blood samples collected were covered for nutrition knowledge and practices related to vitamin A.

\section{Etbical issues}

The study protocol, including the methodology, was approved by the Scientific Advisory Committee of the National Institute of Nutrition (Indian Council of Medical Research; ICMR) and the Steering Committee of NNMB, which consisted of public health specialists (medical), epidemiologists, biostatisticians, nutritionists and social scientists. The study was also approved by the Institutional Ethical Review Board. Written informed consent was obtained from either parent of all children covered in the present study.

\section{Training of the investigators}

Each state team consisted of medical officers, nutritionists and social workers. They were trained at a central reference laboratory (CRL) of NNMB for 3 weeks in identification of signs and symptoms of VAD, data collection on nutrition knowledge and practices of mothers, collection of dried blood spots (DBS), and packing, storing and transporting the same from the field to the laboratory. Care was taken to achieve acceptable intra- and interindividual agreement within the team members and between the state teams for all of the investigations proposed in the present study. A mock survey was carried out in respective states before initiation of the actual survey. To ensure the quality of the data, frequent supervisory visits were made by the team members.

\section{Socio-economic and demographic characteristics}

Information on household sociodemographic characteristics such as community type, literacy status of parents, occupation, type of house, size of land holding, type of family, family size and availability of basic amenities (drinking water, disposal of garbage and sanitary latrine) were collected in all selected households with the help of a pre-tested and validated proforma.

\section{Community system in India}

The Government of India has classified some of its citizens based on their social and economic conditions as scheduled caste (SC), scheduled tribe (ST) and other backward classes (OBC). The SC and ST are Indian population groups that are explicitly recognized by the Indian Constitution and also often called 'underprivileged sections of the society'.

\section{Clinical examination for ocular signs}

Clinical examination for identification of ocular signs of VAD such as conjunctival xerosis, Bitot spots, corneal xerosis, corneal ulcer and keratomalacia was carried out on a total of 71591 pre-school children from 48232 households by the trained investigators. History of night blindness among pre-school children was also obtained from their mothers, using local words for night blindness (e.g. Recheekati, Rathondi). This information was also elicited by asking mothers if their children had any difficulty in playing and/or identifying objects in dim light, especially at sunset.

\section{Knowledge and practices}

Information on knowledge and practices of 2681 mothers of index children on signs and symptoms, causes and consequences of VAD and causes of non-receipt of VAS was also collected with the help of a pre-tested and validated questionnaire. 


\section{Collection of dried blood spots and estimation of serum retinol}

Free-flowing blood from finger puncture was collected in an encircled area on special chromatography filter paper. Two such drops of blood were collected on the same filter paper from each subject. The blood spot was air dried for $1 \mathrm{~h}$ in a box. The DBS samples were then wrapped in black paper, packed in an envelope containing desiccant and sent to CRL by courier, every third day. On arrival, the samples were preserved in a deep freezer at $-20^{\circ} \mathrm{C}$ until analysis. Retinol levels were estimated by the HPLC method ${ }^{(28)}$ at the National Facility for DBS Technology established at the Institute and validated with Craft Technologies, Wilson, NC, USA ${ }^{(29)}$. The maximum duration of storage of any sample before analysis was about 6 months. The stability of retinol in DBS was checked for a period of about 1 year and samples were found to retain retinol levels comparable to the initial levels.

\section{Statistical methods}

Data were analysed using the SPSS for Windows statistical software package version $16 \cdot 0 \cdot 2$ (SPSS Inc., Chicago, IL, USA). Although the survey was carried out in ten states, due to logistical problems the coverage in the states of Gujarat and Uttar Pradesh was $<50 \%$ of target samples and therefore these data were not included in the present analysis.

The data are presented in the form of prevalence of VAD by age and gender. Bivariate analysis was performed by the $\chi^{2}$ test, to study the association between the prevalence of Bitot spots, low serum retinol levels and different sociodemographic variables. Comparisons of means and percentages between groups were made with the $t$ test where appropriate. The significance levels quoted are twotailed. Logistic regression analysis was carried out, after adjusting for age, to assess the risk of developing Bitot spots and variables such as community, religion, literacy status, occupation and household amenities were included in the equation as independent variables. Data presented in the text include percentages, mean, standard deviation and median values, and 95\% confidence intervals. For all tests, $P<0.05$ was considered significant.

\section{Results}

\section{Coverage and profile of the sample}

A total of 71591 children $(51 \cdot 2 \%$ boys) were covered from 48232 households in eight states for clinical assessment and a sub-sample of 3954 children for serum retinol (Fig. 1). The majority of children (42.0\%) belonged to OBC communities, followed by forward castes $(28 \cdot 2 \%)$ and more than a quarter of them belonged to either SC (19.4\%) or ST (10.4\%). The proportion of the underprivileged population (SC/ST) was very high in the states of Madhya Pradesh (40.8\%) and West Bengal $(40 \cdot 3 \%)$. In a majority of households, the major occupation
Table 1 General characteristics of the pre-school children surveyed in rural areas of eight states in India, 2002-2005

\begin{tabular}{lrrr}
\hline Variable & $n$ & $\%$ & $P$ value \\
\hline Gender & & & \\
$\quad$ Boys & 36624 & $51 \cdot 2$ & $<0.001$ \\
$\quad$ Girls & 34967 & $48 \cdot 8$ & \\
Community & & & \\
$\quad$ Scheduled tribet & 7468 & $10 \cdot 4$ & $<0.001$ \\
$\quad$ Scheduled castet & 13886 & $19 \cdot 4$ & \\
$\quad$ Backward caste & 30023 & $42 \cdot 0$ & \\
$\quad$ Othersł & 20214 & $28 \cdot 2$ & \\
Occupation of father & & & \\
$\quad$ Labour & 32462 & $45 \cdot 3$ & $<0.001$ \\
$\quad$ Cultivator & 19361 & $27 \cdot 0$ & \\
$\quad$ Service/business & 14207 & $19 \cdot 9$ & \\
$\quad$ Others & 5561 & $7 \cdot 8$ & \\
Family size & & & \\
$\quad$ 2-4 & 32807 & $45 \cdot 8$ & $<0.001$ \\
$\quad$ Adult female literacy & 38784 & $54 \cdot 2$ & \\
$\quad$ Illiterate & & & \\
$\quad$ Literate & 37406 & $52 \cdot 3$ & $<0.001$ \\
Sanitary latrine in the house & 34124 & $47 \cdot 7$ & \\
$\quad$ Absent & & & \\
$\quad$ Present & 54242 & $75 \cdot 8$ & $<0.001$ \\
\hline
\end{tabular}

tSocially underdeveloped and economically poor.

†Forward caste.

§Artisan such as blacksmith, goldsmith, tailor, basket maker.

of the household head was labour ( $45 \cdot 3 \%)$, followed by agriculture and service/business + others (27\% each). The family size was two to four members in about half of the households. Overall, the prevalence of illiterate adult women was about $52 \%$, its proportion was very high in the states of Madhya Pradesh (76.4\%) and Karnataka $(71 \cdot 0 \%)$. A sanitary latrine was present in about a quarter of households, the prevalence being highest in the state of Kerala and very low in Orissa (7.7\%) and Madhya Pradesh (8.6\%; Table 1).

\section{Ocular signs and symptoms of vitamin A deficiency}

State-wise prevalence of clinical signs and symptoms of VAD among pre-school children is presented in Table 2. The overall prevalence of night blindness, the earliest symptom of VAD, was $0.3 \%$ and it was highest in the states of Maharashtra (1.1\%) and Madhya Pradesh $(0 \cdot 8 \%)$. The prevalence of conjunctival xerosis among pre-school children was $1 \cdot 8 \%$ and it was highest in the states of Madhya Pradesh (4.9\%), followed by West Bengal $(3 \cdot 7 \%)$ and Karnataka $(2 \cdot 2 \%)$. Overall, the prevalence of Bitot spots was $0 \cdot 8 \%$. In six out of eight states surveyed, the prevalence of Bitot spots was higher than $0.5 \%$; it was the highest in the state of Madhya Pradesh (1.4\%), followed by Maharashtra (1.3\%) and Andhra Pradesh $(1 \cdot 2 \%)$. The national-level prevalence of ocular signs and symptoms of VAD was $2 \cdot 3 \%$, being higher in the states of Madhya Pradesh (6.6\%) and West Bengal $(3 \cdot 8 \%)$ compared with the other states.

The prevalence of VAD by age group and gender is presented in Table 3. The prevalence of all forms of 
Table 2 Prevalence (\%) of ocular signs and symptoms of vitamin A deficiency (VAD) by state among rural pre-school children, India, 2002-2005

\begin{tabular}{|c|c|c|c|c|c|}
\hline State & $n$ & Night blindness & Conjunctival xerosis & Bitot spots & Total VAD \\
\hline Kerala & 8329 & 0.0 & 0.1 & 0.0 & 0.1 \\
\hline Tamil Nadu & 9197 & $0 \cdot 1$ & 0.2 & 0.5 & 0.6 \\
\hline Karnataka & 8627 & 0.2 & $2 \cdot 2$ & 0.7 & $2 \cdot 8$ \\
\hline Andhra Pradesh & 9327 & 0.2 & $1 \cdot 3$ & $1 \cdot 2$ & $2 \cdot 1$ \\
\hline Maharashtra & 8646 & $1 \cdot 1$ & $1 \cdot 3$ & $1 \cdot 3$ & 1.9 \\
\hline Madhya Pradesh & 8777 & $0 \cdot 8$ & 4.9 & $1 \cdot 4$ & $6 \cdot 6$ \\
\hline Orissa & 9460 & $0 \cdot 1$ & 0.3 & 0.3 & 0.4 \\
\hline West Bengal & 9228 & 0.2 & $3 \cdot 7$ & 0.6 & $3 \cdot 8$ \\
\hline Pooled & 71591 & $0 \cdot 3$ & $1 \cdot 8$ & $0 \cdot 8$ & $2 \cdot 3$ \\
\hline
\end{tabular}

Table 3 Prevalence (\%) of ocular signs and symptoms of vitamin A deficiency (VAD) by age and gender among rural pre-school children, eight states in India, 2002-2005

\begin{tabular}{lcccccc}
\hline Age/gender & $n$ & Normal & Night blindness & Conjunctival xerosis & Bitot spots & Total VAD \\
\hline $\begin{array}{l}\text { Gender } \\
\text { Boys }\end{array}$ & 36624 & $97 \cdot 4$ & $0 \cdot 4$ & & & \\
$\quad$ Girls & 34967 & $98 \cdot 1$ & $0 \cdot 3$ & $1 \cdot 4$ & $0 \cdot 9^{\star}$ & $2 \cdot 6^{\star}$ \\
Age (years) & & & & & $0 \cdot 6$ & $1 \cdot 9$ \\
1 & 13906 & $99 \cdot 7$ & $0 \cdot 0^{\mathrm{a}}$ & $0 \cdot 2^{\mathrm{a}}$ & $0 \cdot 1^{\mathrm{a}}$ & $0 \cdot 3^{\mathrm{a}}$ \\
2 & 16768 & $98 \cdot 8$ & $0 \cdot 2^{\mathrm{b}}$ & $1 \cdot 0^{\mathrm{b}}$ & $0 \cdot 4^{\mathrm{b}}$ & $1 \cdot 2^{\mathrm{b}}$ \\
3 & 17359 & $97 \cdot 6$ & $0 \cdot 4^{\mathrm{c}}$ & $1 \cdot 8^{\mathrm{c}}$ & $0 \cdot 8^{\mathrm{c}}$ & $2 \cdot 4^{\mathrm{c}}$ \\
4 & 23558 & $95 \cdot 8$ & $0 \cdot 6^{\mathrm{d}}$ & $3 \cdot 2^{\mathrm{d}}$ & $1 \cdot 4^{\mathrm{d}}$ & $4 \cdot 2^{\mathrm{d}}$ \\
Pooled & 71591 & $97 \cdot 7$ & $0 \cdot 3$ & $1 \cdot 8$ & $0 \cdot 8$ & $2 \cdot 3$ \\
$P$ value & - & - & $<0 \cdot 001$ & $<0 \cdot 001$ & $<0 \cdot 001$ & $<0 \cdot 001$ \\
\hline
\end{tabular}

a,b,c,dPrevalences within a column with unlike superscript letters were significantly different among ages $(P<0.001)$. ${ }^{*}$ Prevalence was significantly different from that in girls: $P<0 \cdot 001$.

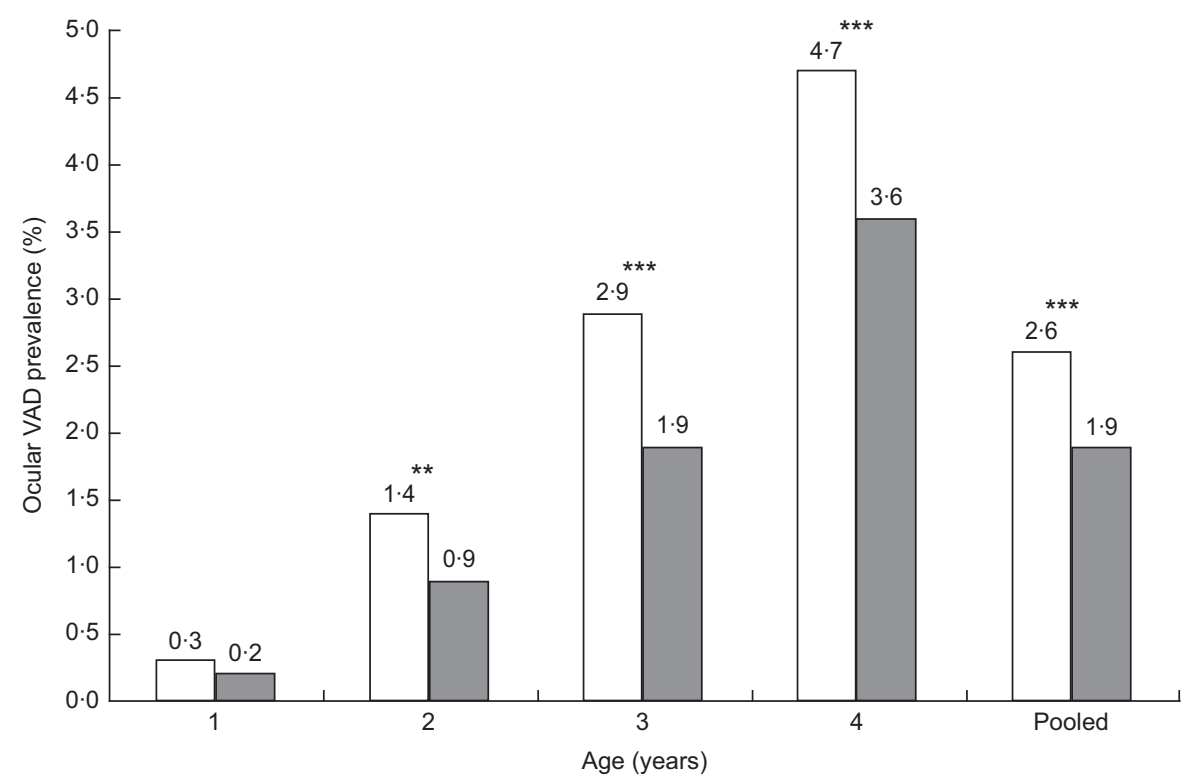

Fig. 2 Ocular prevalence of vitamin A deficiency (VAD) by age and gender ( $\square$, boys; $\square$, girls) among rural pre-school children, eight states in India, 2002-2005. Gender differentials were observed in all age groups of children, except 1 -year-olds $\left({ }^{* \star} P<0 \cdot 01\right.$; $\left.{ }^{* \star \star} P<0.001\right)$

clinical symptoms and signs of ocular VAD was significantly $(P<0.001)$ higher among boys $(2 \cdot 6 \%)$ compared with girls $(1.9 \%)$ and was observed at all ages (Fig. 2). The prevalence of Bitot spots increased with age $(0 \cdot 1-1 \cdot 4 \%)$.

\section{Mean serum retinol concentrations}

The mean serum retinol concentration was $18 \cdot 3$ (SD 9.92) $\mu \mathrm{g} / \mathrm{dl}$, ranging from $2 \mu \mathrm{g} / \mathrm{dl}$ to $90 \mu \mathrm{g} / \mathrm{dl}$. No gender differentials were observed in the mean retinol concentration. However, it was significantly $(P<0 \cdot 05)$ lower 
among children above 4 years of age $(17.5 \mu \mathrm{g} / \mathrm{dl})$ compared with younger ages $(19 \cdot 0 \mu \mathrm{g} / \mathrm{dl})$.

\section{Subclinical vitamin A deficiency}

The overall prevalence of subclinical VAD (serum retinol $<20 \mu \mathrm{g} / \mathrm{dl}$ ) among pre-school children was about $62 \%$ and it was significantly higher $(P<0 \cdot 01)$ in the children aged 4 years old $(65.6 \%)$ compared with all other ages (58-60\%). There were no gender differentials observed in the prevalence of serum retinol $<20 \mu \mathrm{g} / \mathrm{dl}$ (Table 4). However, it varied from state to state and it was highest in the states of Madhya Pradesh (88\%) and Kerala (79\%), while it was lowest in Karnataka (52\%) and Tamil Nadu (49\%). It increased with increasing age in all of the states, except in Madhya Pradesh, Maharashtra and Orissa.

\section{Determinants of vitamin A deficiency}

Determinants of Bitot spots and serum retinol $<20 \mu \mathrm{g} / \mathrm{dl}$ are presented in Table 5. The proportion of pre-school children with Bitot spots was significantly higher

Table 4 Serum retinol concentrations $(\mu \mathrm{g} / \mathrm{dl})$ and prevalence $(\%)$ of subclinical vitamin A deficiency (VAD; serum retinol $<20 \mu \mathrm{g} / \mathrm{dl}$ ) by age and gender among rural pre-school children, eight states in India, 2002-2005

\begin{tabular}{lrrrcc}
\hline Age/gender & $n$ & Mean & \multicolumn{1}{c}{ SD } & Median & Subclinical VAD \\
\hline Gender & & & & & \\
$\quad$ Boys & 1985 & $18 \cdot 5$ & $10 \cdot 2$ & $17 \cdot 2$ & $60 \cdot 8$ \\
$\quad$ Girls & 1949 & $18 \cdot 0$ & $9 \cdot 6$ & $16 \cdot 5$ & $62 \cdot 8$ \\
Age (years) & & & & & \\
1 & 562 & $19 \cdot 0^{\mathrm{a}}$ & $10 \cdot 15$ & $17 \cdot 6$ & $58 \cdot 2^{\mathrm{a}}$ \\
2 & 929 & $18 \cdot 4^{\mathrm{a}}$ & $10 \cdot 58$ & $16 \cdot 8$ & $60 \cdot 4^{\mathrm{a}}$ \\
3 & 1096 & $18 \cdot 7^{\mathrm{a}}$ & $10 \cdot 13$ & $17 \cdot 4$ & $60 \cdot 1^{\mathrm{a}}$ \\
4 & 1347 & $17 \cdot 5^{\mathrm{b}}$ & $9 \cdot 10$ & $16 \cdot 0$ & $65 \cdot 6^{\mathrm{b}}$ \\
Pooled & 3954 & $18 \cdot 3$ & $9 \cdot 92$ & $16 \cdot 8$ & $61 \cdot 8$ \\
\hline
\end{tabular}

${ }^{a, b}$ Mean values within a column with unlike superscript letters were significantly different among ages $(P<0.05)$.
$(P<0 \cdot 001)$ among ST and SC $(1 \cdot 2-1 \cdot 4 \%)$ than in the other communities $(0 \cdot 4-0 \cdot 6 \%)$. The prevalence was significantly higher $(P<0 \cdot 001)$ among the children of labourers $(1 \cdot 0 \%)$, illiterate mothers $(1 \cdot 1 \%)$ and households with larger family size $(0 \cdot 9 \%)$.

The proportion of children with serum retinol $<20 \mu \mathrm{g} / \mathrm{dl}$ was significantly higher $(P<0 \cdot 05)$ among the children belonging to ST $(74 \cdot 1 \%)$ than among all other communities $(58-63 \%)$. Children of illiterate mothers $(62 \cdot 8 \%)$ and in households where the head's occupation was service/ business $(64 \cdot 2 \%)$ or labour $(62 \cdot 7 \%)$ showed marginally higher prevalences of serum retinol $<20 \mu \mathrm{g} / \mathrm{dl}$.

The risk of VAD and its association with different determinants (socio-economic factors) was compared by calculating odds ratios with unconditional logistic regression and adjusting for age and gender (Table 6). The odds of having Bitot spots was significantly higher among the pre-school children who belonged to SC $(\mathrm{OR}=3 \cdot 8 ; 95 \%$ CI $2 \cdot 9,5 \cdot 0)$ or $\mathrm{ST}(\mathrm{OR}=3 \cdot 1 ; 95 \% \mathrm{CI} 2 \cdot 3$, $4 \cdot 2)$ compared with other communities after adjusting for age. Similarly, the risk of Bitot spots was significantly higher among children of Hindu religion (OR $=3 \cdot 0 ; 95 \%$ CI $1 \cdot 9,4 \cdot 7)$ compared with the children of Muslims and others. The risk was significantly higher among the children of labourers (OR $=2 \cdot 9 ; 95 \%$ CI $2 \cdot 1,3 \cdot 9)$ compared with other occupations. The odds of having Bitot spots was significantly higher among children from households with family size of more than four members $(\mathrm{OR}=1 \cdot 5$; $95 \%$ CI $1 \cdot 2,1 \cdot 8)$ compared with family size of two to four. The odds of having Bitot spots was also significantly higher among the children of illiterate mothers $(\mathrm{OR}=2.7$; $95 \%$ CI $2 \cdot 2,3 \cdot 3$ ) and children from households without a sanitary latrine $(\mathrm{OR}=5 \cdot 9 ; 95 \% \mathrm{CI} 4 \cdot 0,8 \cdot 7)$. The odds ratio for serum retinol $<20 \mu \mathrm{g} / \mathrm{dl}$ was 1.5 times higher $(\mathrm{OR}=1 \cdot 5 ; 95 \% \mathrm{CI} 1 \cdot 0,2 \cdot 3)$ among children who did not receive at least one dose of VAS compared with those

Table 5 Determinants of Bitot spots and subclinical vitamin A deficiency (VAD; serum retinol $<20 \mu \mathrm{g} / \mathrm{dl}$ ) among rural pre-school children, eight states in India, 2002-2005

\begin{tabular}{|c|c|c|c|c|c|c|}
\hline Variable & $n$ & Bitot spots (\%) & $P$ value & $n$ & Subclinical VAD (\%) & $P$ value \\
\hline \multicolumn{7}{|l|}{ Community } \\
\hline Scheduled tribe & 7468 & $1 \cdot 2$ & \multirow[t]{4}{*}{$<0.001$} & 370 & $74 \cdot 1$ & \multirow[t]{4}{*}{$<0.001$} \\
\hline Scheduled caste & 13886 & $1 \cdot 4$ & & 676 & $57 \cdot 7$ & \\
\hline Backward caste & 30023 & $0 \cdot 6$ & & 1646 & $62 \cdot 9$ & \\
\hline Otherst & 20214 & $0 \cdot 4$ & & 1242 & $58 \cdot 8$ & \\
\hline \multicolumn{7}{|l|}{ Occupation } \\
\hline Labourer & 32462 & $1 \cdot 0$ & \multirow[t]{4}{*}{$<0.001$} & 1762 & $62 \cdot 7$ & \multirow[t]{4}{*}{0.088} \\
\hline Cultivators & 19361 & $0 \cdot 6$ & & 1081 & $59 \cdot 4$ & \\
\hline Service/business & 14207 & $0 \cdot 4$ & & 794 & $64 \cdot 2$ & \\
\hline Others $\ddagger$ & 5561 & 0.5 & & 309 & $58 \cdot 6$ & \\
\hline \multicolumn{7}{|l|}{ Family size } \\
\hline $2-4$ & 32807 & $0 \cdot 6$ & \multirow[t]{2}{*}{$<0.001$} & 1795 & $60 \cdot 5$ & \multirow[t]{2}{*}{$0 \cdot 143$} \\
\hline$\geq 4$ & 38785 & 0.9 & & 2139 & $62 \cdot 8$ & \\
\hline \multicolumn{7}{|l|}{ Female literacy } \\
\hline Illiterate & 37406 & $1 \cdot 1$ & \multirow[t]{2}{*}{$<0.001$} & 2037 & $62 \cdot 8$ & \multirow[t]{2}{*}{0.153} \\
\hline Literate & 34124 & $0 \cdot 4$ & & 1897 & $60 \cdot 6$ & \\
\hline
\end{tabular}

tForward caste.

‡Artisan such as blacksmith, goldsmith, tailor, basket maker. 
Table 6 Risk factors associated with the prevalence of Bitot spots and subclinical vitamin A deficiency (VAD; serum retinol $<20 \mu \mathrm{g} / \mathrm{dl}$ ), adjusted for and gender among rural pre-school children, eight states in India, 2002-2005

\begin{tabular}{|c|c|c|c|c|}
\hline \multirow[b]{2}{*}{ Variable } & \multicolumn{2}{|c|}{ Bitot spots } & \multicolumn{2}{|c|}{ Subclinical VAD } \\
\hline & OR & $95 \% \mathrm{Cl}$ & OR & $95 \% \mathrm{Cl}$ \\
\hline \multicolumn{5}{|l|}{ Community } \\
\hline Otherst & $1 \cdot 0$ & & $1 \cdot 0$ & \\
\hline Scheduled tribe & $3 \cdot 1^{*}$ & $2 \cdot 3,4 \cdot 2$ & $2 \cdot 0^{*}$ & $1 \cdot 5,2 \cdot 6$ \\
\hline Scheduled caste & $3 \cdot 8^{\star}$ & $2 \cdot 9,5 \cdot 0$ & 0.9 & $0 \cdot 8,1 \cdot 1$ \\
\hline Backward class & $1 \cdot 6^{*}$ & $1 \cdot 9,2 \cdot 4$ & $1 \cdot 2^{*}$ & $1 \cdot 0,1 \cdot 4$ \\
\hline \multicolumn{5}{|l|}{ Religion } \\
\hline Muslim & $1 \cdot 0$ & & $1 \cdot 0$ & \\
\hline Buddhist & 0.9 & $0 \cdot 4,2 \cdot 2$ & 0.9 & $0 \cdot 6,1 \cdot 5$ \\
\hline Hindu & $3 \cdot 0^{*}$ & $1 \cdot 9,4 \cdot 7$ & $0 \cdot 7^{*}$ & $0 \cdot 5,0 \cdot 8$ \\
\hline \multicolumn{5}{|l|}{ Occupation } \\
\hline Business/service & $1 \cdot 0$ & & $1 \cdot 0$ & \\
\hline Labourer & $2 \cdot 9^{*}$ & $2 \cdot 1,3 \cdot 9$ & 0.9 & $0 \cdot 8,1 \cdot 1$ \\
\hline Cultivator & $1 \cdot 8^{*}$ & $1 \cdot 3,2 \cdot 5$ & $0 \cdot 8^{*}$ & $0 \cdot 7,1 \cdot 0$ \\
\hline Others $\ddagger$ & $1 \cdot 4$ & $0 \cdot 9,2 \cdot 3$ & $0 \cdot 8$ & $0 \cdot 6,1 \cdot 1$ \\
\hline \multicolumn{5}{|l|}{ Family size } \\
\hline $2-4$ & $1 \cdot 0$ & & $1 \cdot 0$ & \\
\hline$\geq 4$ & $1 \cdot 5^{\star}$ & $1 \cdot 2,1 \cdot 8$ & $1 \cdot 1^{*}$ & $1 \cdot 0,1 \cdot 3$ \\
\hline \multicolumn{5}{|l|}{ Female literacy } \\
\hline Literate & $1 \cdot 0$ & & $1 \cdot 0$ & \\
\hline Illiterate & $2 \cdot 7^{\star}$ & $2 \cdot 2,3 \cdot 3$ & $1 \cdot 1$ & $0 \cdot 9,-1 \cdot 2$ \\
\hline \multicolumn{5}{|l|}{ Sanitary latrine } \\
\hline Present & $1 \cdot 0$ & & $1 \cdot 0$ & \\
\hline Absent & $5 \cdot 9^{*}$ & $4 \cdot 0,8 \cdot 7$ & $0 \cdot 8^{*}$ & $0 \cdot 7,1 \cdot 0$ \\
\hline \multicolumn{5}{|c|}{ Vitamin A supplementation } \\
\hline Received & $1 \cdot 0$ & & $1 \cdot 0$ & \\
\hline Not received & $2 \cdot 7$ & $0 \cdot 4,16 \cdot 7$ & $1 \cdot 5^{\star}$ & $1 \cdot 0,2 \cdot 3$ \\
\hline
\end{tabular}

${ }^{*} \mathrm{OR}$ was significantly different from that of the reference category: $P<0.05$. tForward caste.

‡Artisan such as blacksmith, goldsmith, tailor, basket maker.

who received it. Similarly, it was double $(\mathrm{OR}=2 \cdot 0 ; 95 \%$ CI $1.5,2 \cdot 6$ ) among children of ST communities and $1 \cdot 2$ times higher $(\mathrm{OR}=1 \cdot 2 ; 95 \% \mathrm{CI} 1 \cdot 0,1 \cdot 4)$ among children belonging to backward classes (Table 6).

\section{Knowledge and practices of mothers}

About half ( $41 \%)$ of mothers of the pre-school children were aware of night blindness followed by total blindness ( $8 \%)$ and Bitot's spots $(4 \%)$ as the manifestations of VAD. About $12 \%$ of mothers attributed ocular signs and symptoms of VAD due to vitamin A deficiency and 14\% due to dietary inadequacy of vitamin A. About $10 \%$ of the mothers stated that VAD could be prevented through dietary modification by including leafy vegetables, yellow and orange coloured fruits, and animal foods in the diet of the child. In the case of VAD, about a third of mothers stated that they had consulted doctors for treatment.

About $58 \%$ of mothers stated that their children had received at least one dose of VAS during the preceding year, while only a quarter of them had received the stipulated two doses of vitamin A in the reporting year. More than a third of mothers stated they were not aware of the existence of the VAS programme and half of them reported that their children were never offered the VAS and that time and place of VAS were not convenient.
However, half of the mothers knew that VAS is beneficial for eye health of the child. Only $13 \%$ of mothers reported they had received health and nutrition education on signs and symptoms $(5 \cdot 3 \%)$, the consequences of severe VAD $(4 \cdot 4 \%)$, the VAS programme $(6 \cdot 5 \%)$ and the consumption of green leafy vegetables and fruits (9.7\%).

\section{Discussion}

The present study, perhaps for the first time in India, has provided a large database on the vitamin A status of rural pre-school children by covering state-representative samples. Although the prevalence of severe forms of ocular signs such as corneal ulcers and keratomalacia has in general become very rare, the milder forms of ocular signs such as Bitot spots, conjunctival xerosis and night blindness are still prevalent among children in developing countries $^{(30)}$. In the present study the prevalence of Bitot spots was above $0.5 \%$ in six out of eight states surveyed. The lower prevalence of Bitot spots in the state of Orissa may perhaps be due to the large coverage of children by the VAS programme as a special drive along with pulse polio immunisation during the period of the survey.

The prevalence of Bitot spots is in fact above the WHO cut-off level for considering VAD as a public health problem and signifies that it is still a public health problem among pre-school children of India ${ }^{(21,31)}$. However, the prevalence of ocular signs of VAD observed in Indian states is lower than the figures reported from other developing countries like Ethiopia $(2 \cdot 2 \%)$ in Africa ${ }^{(32)}$. This may be due to the implementation of VAS.

The study revealed that although the prevalence of ocular signs of VAD among pre-school children in rural areas is low, the prevalence of subclinical VAD defined by serum retinol $<20 \mu \mathrm{g} / \mathrm{dl}$ is extremely high (62\%). A National Institute of Nutrition/WHO/UNICEF study carried out in the same period also showed a high prevalence of low serum retinol levels in Orissa $(63.8 \%)$ and Andhra Pradesh $(52 \cdot 3 \%)^{(33)}$. The prevalence of retinol concentrations $<20 \mu \mathrm{g} / \mathrm{dl}$ was highest in the states of Madhya Pradesh and Kerala compared with the remaining states. These figures are higher than those in other developing or underdeveloped countries like Sri Lanka $(8 \cdot 2 \%)^{(34)}$, Columbia $(14 \%)^{(35)}$, Nigeria $(29 \cdot 5 \%)^{(36)}$ and Ethiopia $(51 \%)^{(32)}$.

In developing countries, the major source of vitamin A is through dietary intake of foods rich in provitamin A. However various surveys have indicated that poor intakes of animal-source foods and fruits and vegetables rich in provitamin A carotenoids ${ }^{(37)}$, coupled with a low fat intake, results in $\operatorname{VAD}^{(35,38)}$ especially among young children $^{(39)}$.

The RDA ${ }^{(37)}$ for retinol in pre-school children is $400 \mu \mathrm{g}$ or $3200 \mu \mathrm{g}$ for $\beta$-carotene considering a conversion ratio of $1: 8$. This is achievable through a sufficient intake of 
either animal foods or yellow fruits and vegetables, along with an adequate amount of fat for micellarization, absorption and bioconversion of $\beta$-carotene to vitamin $\mathrm{A}$. In the absence of informed dietary diversification, it may be extremely difficult to meet the RDA for vitamin A in pre-school children, necessitating VAS. Surveys carried out in different parts of India suggest a low consumption of these foods ${ }^{(40-42)}$ and NNMB surveys have revealed that $88 \%$ of children are not meeting even $50 \%$ of the suggested dietary intake of vitamin $\mathrm{A}^{(37)}$. Thus these diet surveys are also supporting the need for VAS and to enhance its coverage in India.

We observed a higher prevalence of VAD among children of the older age group compared with younger age groups. This may reflect a cumulative effect of poor dietary intake and non-coverage in the older children for VAS. This finding formed the basis for the Ministry of Health and Family Welfare, Government of India to modify the VAS programme by extending the age of beneficiaries from 36 to 59 months from $2007^{(43)}$.

In developing countries, there are socio-economic and cultural determinants that can also lead to low dietary intakes, especially of micronutrients ${ }^{(37,40)}$. The association between the prevalence of Bitot spots and different sociodemographic factors revealed that the prevalence was significantly $(P<0 \cdot 001)$ higher among children belonging to socio-economically underdeveloped sections of society such as SC/ST communities. Also, those preschool children residing in households with no sanitary latrine had a higher prevalence of both ocular signs of VAD and low serum retinol levels, observations that are consistent with other studies ${ }^{(44)}$.

The VAS programme for pre-school children has been in operation in India for more than three decades but the rate of coverage was reported as low ${ }^{(45)}$. Children with ocular signs of VAD have been reported to be at greater risk of morbidity than those without ${ }^{(46)}$. The effect of VAS on morbidity and mortality has been controversial because of the inconsistent results ${ }^{(6,47)}$. This could be due to the adoption of varying degrees of ocular signs of VAD to define the impact and it is conceivable that VAS is likely to have a greater effect in areas where VAD is highly prevalent. However, considering the magnitude of both ocular and low serum retinol levels in Indian states, it may be logical to consider universal rather than targeted VAS. Moreover, only a very small percentage $(13 \%)$ of the mothers received nutrition education on VAD and most of the mothers were unaware of the VAS programme. Therefore there is a need to strengthen and devise innovative methods of nutrition education.

It is well known that high morbidity rates in a population can precipitate ocular signs of VAD by decreasing intake and absorption, and increasing excretion, of retinol. Although we have not assessed morbidity in the present study, based on investigations carried out in the same population, a $5 \%$ rate of acute morbidity like fever, diarrhoea, dysentery and respiratory infections in $2001^{(20)}$ and a $15 \%$ rate in $2005^{(22)}$ have been reported. Thus, morbidity may not be influencing serum retinol to any significant extent.

According to the third National Family Health Survey (2005-2006), the rate of national coverage for at least one dose of vitamin A (linked with immunisation) is $<50 \%{ }^{(48)}$. However, the national consultation on vitamin A recommended strengthening of the ongoing VAS programme linked with routine immunisation to achieve $90 \%$ coverage for at least the first two doses ${ }^{(49)}$.

The present results reiterate that VAD still exists as a public health problem in India, the rate of VAS coverage is very poor and dietary intakes of vitamin A are negligible. There is a need for continued efforts to improve the vitamin A status of pre-school children by strengthening the existing VAS programme ${ }^{(50)}$ and duly addressing the logistical problems appropriately ${ }^{(51)}$. VAS is the simplest way to improve vitamin A status and is the favoured strategy in areas where the problem is widely prevalent. In countries like India, where deficiencies of multiple micronutrients are not uncommon, supplementation with multiple micronutrients may also be considered along with dietary diversification, which would undoubtedly be the most logical and sustainable strategy to prevent $\operatorname{VAD}^{(52,53)}$. Furthermore, fortified staple foods should be considered in all of the supplementary feeding programmes aimed at pre-school children ${ }^{(54)}$.

\section{Limitations of the study}

C-reactive protein and worm load were not investigated in the present study.

\section{Acknowledgements}

This work was supported by the ICMR, Department of Health Research, Government of India. No conflict of interest was declared. A.L. developed the study protocol, participated in the child screening and assessment, and wrote the manuscript. M.N.K. developed standard operating procedures for collection of DBS, carried out estimation of serum retinol levels from DBS, and provided advice in interpretation and presentation of results. N.A. participated in the child screening and assessment. P.R. assisted in estimation of serum retinol levels from DBS. N.B. carried out sampling and statistical analysis and provided advice on study design. K.M.R., C.G., S.K. and M.R. participated in the child screening and assessment. V.V.R. assisted in estimation of serum retinol levels from DBS. G.N.V.B. developed the study protocol and provided advice on interpretation and presentation of results. The authors thank the parents and children for their participation in the study; the Director General, ICMR, for financial support; the Director of the National Institute of Nutrition for his support and cooperation in carrying out the study; all staff of the NNMB, including the medical officers, 
nutritionists and social workers who were involved in data collection; and technical staff of the Division of Community Studies for their technical support.

\section{References}

1. West KP Jr (2002) Extent of vitamin A deficiency among preschool children and women of reproductive age. J Nutr 132, 9 Suppl., 2857S-2866S.

2. Ways V, Yusafzai A, Mogale K et al. (2004) Association of sub-clinical vitamin A deficiency with severe acute respiratory infection in Indian children under 5 years. Eur J Clin Nutr 58, 563-567.

3. Milton RC, Reddy V \& Naidu AN (1987) Mild vitamin A deficiency and childhood mortality - an Indian experience. Am J Clin Nutr 46, 827-829.

4. Grotto I, Mimouni M, Gdalevich M et al. (2003) Vitamin A supplementation and childhood morbidity from diarrhoea and respiratory infections: a meta analysis. J Pediatr 142, 297-304.

5. Thurnham DI, McCabe GP, Northrop-Clewes CA et al. (2003) Effect of sub clinical infection on plasma concentrations and assessment of prevalence of vitamin A deficiency: meta analysis. Lancet 362, 2052-2058.

6. Gupta P \& Indrayan A (2003) Effect of vitamin A supplementation on childhood morbidity and mortality: critical review of Indian studies. Indian J Pediatr 39, 1099-1108.

7. Blackfan KD \& Wolbach SB (1993) Vitamin A deficiency in infants: a clinical and pathological study. J Pediatr 3, 679-706.

8. Villamor E \& Fawzi WW (2005) Effect of vitamin A supplementation on immune responses and correlation with clinical outcomes. Clin Microbiol Rev 18, 446-464.

9. Sommer A, Katz J \& Tarwotjo I (1984) Increased risk of respiratory disease and diarrhoea in children with preexisting mild vitamin A deficiency. Am J Clin Nutr 40, 1090-1095.

10. Bhaskaram P (2002) Micronutrient malnutrition, infection, and immunity: an overview. Nutr Rev 60, 5 Pt 2, S40-S45.

11. UNICEF \& The Micronutrient Initiative (2005) Vitamin A and Mineral Deficiency: A Global Progress Report, p. 4. http://www.micronutrient.org/CMFiles/PubLib/Report-67VMD-A-Global-Damage-Assessment-Report1KSB-32420089634.pdf (accessed November 2010).

12. Toteja GS, Singh P, Dhillon BS et al. (2002) Vitamin A deficiency disorders in 16 districts of India. Indian J Pediatr 69, 603-605.

13. Reddy V, Prahlad Rao N, Gowrinath Sastry J et al. (1993) Nutrition Trends in India. Hyderabad: National Institute of Nutrition, Indian Council of Medical Research.

14. World Health Organization (2002) Global Prevalence of Vitamin A Deficiency. WHO Working Paper no. 2. Geneva: WHO.

15. World Health Organization (2009) Global Prevalence of Vitamin A Deficiency (1995-2005). Geneva: WHO.

16. Ministry of Health and Family Welfare, Government of India (1997) Report of Workshop to Review Programs for Control of Vitamin A Deficiency in India. New Delhi: Ministry of Health and Family Welfare, Government of India.

17. National Nutrition Monitoring Bureau (1991) Diet and Nutritional Status of Rural Population: First Repeat Survey. NNMB Technical Report no. 13. Hyderabad: National Institute of Nutrition, Indian Council of Medical Research.

18. National Nutrition Monitoring Bureau (1999) Diet and Nutritional Status of Rural Population: Second Repeat Survey. NNMB Technical Report no. 18. Hyderabad: National Institute of Nutrition, Indian Council of Medical Research.
19. National Nutrition Monitoring Bureau (2000) Dynamic Database on Diet and Nutrition. Hyderabad: National Institute of Nutrition, Indian Council of Medical Research; available at http://www.nnmbindia.org/NNMB\%20MND \%20REPORT\%202004-Web.pdf

20. National Nutrition Monitoring Bureau (2002) Diet and Nutritional Status of Rural Population. NNMB Technical Report no. 21. Hyderabad: National Institute of Nutrition, Indian Council of Medical Research.

21. National Nutrition Monitoring Bureau (2003) Prevalence of Micronutrient Deficiencies. NNMB Technical Report no. 22. Hyderabad: National Institute of Nutrition, Indian Council of Medical Research.

22. National Nutrition Monitoring Bureau (2006) Prevalence of Vitamin A Deficiency Among Preschool Children in Rural Areas. NNMB Technical Report no. 23. Hyderabad: National Institute of Nutrition, Indian Council of Medical Research.

23. Arlappa N, Laxmaiah A, Balakrishna N et al. (2008) Clinical and sub-clinical vitamin A deficiency among rural preschool children of Maharashtra, India. Ann Hum Biol 35, 606-614.

24. Arlappa N, Balakrishna N, Laxmaiah A et al. (2011) Prevalence of clinical and sub-clinical vitamin A deficiency among rural preschool children of West Bengal, India. Indian Pediatr 48, 47-49.

25. Arlappa N, Balakrishna N, Laxmaiah A et al. (2011) Prevalence of vitamin A deficiency and its determinants among the rural pre-school children of Madhya Pradesh, India. Ann Hum Biol 38, 131-136.

26. Arlappa N, Laxmaiah A, Balakrishna N et al. (2011) Micronutrient deficiency disorders among the rural children of West Bengal, India. Ann Hum Biol 38, 281-289.

27. National Sample Survey Organization (1998) 54th Round of Consumer Expenditure Survey. New Delhi: Ministry of Statistics and Programme Implementation, Government of India.

28. National Institute of Nutrition (2005-2006) External Validation of the National Facility for Dried Blood Spot Technology for Vitamin A Estimation Annual Report, p. 18. Hyderabad: National Institute of Nutrition, Indian Council of Medical Research.

29. Craft NE, Bulux J, Valdez C et al. (2000) Retinal concentration in capillary dried blood spots from healthy volunteers: method validation. Am J Clin Nutr 72, 450-454.

30. Ghana VAST Study Team (1993) Vitamin A supplementation in northern Ghana: effects on clinic attendances, hospital admissions and child mortality. Lancet 342, 7-12.

31. World Health Organization (1996) Indicators for Assessing Vitamin A Deficiency and Their Application in Monitoring and Evaluating Intervention Programmes. Geneva: WHO.

32. Asrat YT, Omwega AM \& Muita JW (2002) Prevalence of vitamin A deficiency among pre-school and schoolaged children in Arsi Zone, Ethiopia. East Afr Med J 79, 355-359.

33. Gorstein J, Bhaskaram P, Khanum S et al. (2003) Safety and impact of vitamin A supplementation delivered with oral vaccine as part of the immunization campaign in Orissa, India. Food Nutr Bull 24, 319-331.

34. Mahawithanage ST, Kannangara KK, Wickremasinghe R et al. (2007) Impact of vitamin A supplementation on health status and absenteeism of school children in Sri Lanka. Asia Pac J Clin Nutr 16, 94-102.

35. Maslova E, Mora-Plazas M, Forero Y et al. (2009) Are vitamin $\mathrm{A}$ and iron deficiencies re-emerging in urban Latin America? A survey of school children in Bogota, Colombia. Food Nutr Bull 30, 103-111.

36. Maziya-Dixon BB, Akinyele IO, Sanusi RA et al. (2006) Vitamin A deficiency is prevalent in children less than $5 \mathrm{y}$ of age in Nigeria. J Nutr 136, 2255-2261. 
37. Indian Council of Medical Research (1990) Nutrient Requirements and Recommended Dietary Allowances for Indians. A Report of the Expert Group of the Indian Council of Medical Research. New Delhi: Indian Council of Medical Research.

38. Edem DO (2009) Vitamin A: a review. Asian J Clin Nutr 1 , 65-82.

39. Combs GF (2008) The Vitamins: Fundamental Aspects in Nutrition and Health, 3rd ed. Burlington, MA: Elsevier Academic Press.

40. Nelson E, Williams C, Graham N et al. (2004) Nutrition and infectious diseases. In Infectious Disease Epidemiology: Theory and Practice, pp. 289-291. Sudbury, MA: Jones and Bartlett Publishers.

41. Usha R, Reynaldo M, Michael C et al. (1999) Dietary vitamin A intakes of preschool-age children in South India. J Nutr 129, 2021-2027.

42. National Nutrition Monitoring Bureau (2005-2006) Diet and Nutritional Status of Rural Population. NNMB Technical Report no. 24. Hyderabad: National Institute of Nutrition, Indian Council of Medical Research.

43. Government of India, Ministry of Health and Family Welfare, Department of Family Welfare, Child Health Division (2006) Order no. Z.28020/30/2003-CH dated 2 November 2006. New Delhi: Ministry of Health and Family Welfare, Government of India.

44. Jiang J, Toschke AM, Von Kries R et al. (2006) Vitamin A status among children in China. Public Health Nutr 9, 955-960.

45. Ministry of Health and Family Welfare, Government of India (2010) Child Health. http://mohfw.nic.in/ dofw\%20 website/Brief\%20Note\%20on\%20CH.doc (accessed October 2010).
46. Sommer A, Hussaini G, Tarwotjo I et al. (1983) Increased mortality in children with mild vitamin A deficiency. Lancet 2, 585-588.

47. Choudhary P (2000) Does India Need Vitamin A Mega Dose Supplementation for Children? A Report of National Consultation on Benefits and Safety of Vitamin A Administration to Preschool Children and Pregnant and Lactating Women [KU Srivastava, editor]. New Delhi: Ministry of Health and Family Welfare.

48. International Institute of Population Sciences (2005-2006) National Family Health Survey-3. Mumbai: IIPS.

49. Ministry of Health and Family Welfare, Government of India (2000) A Report on National Consultation on Benefits and Safety of Vitamin A Administration to Preschool Children and Pregnant and Lactating Women. Conclusions and Recommendations. New Delhi: Ministry of Health and Family Welfare, Government of India.

50. Sethi V \& Kapil U (2003) Reduction in prevalence of Bitot's spots after administration of mega dose of vitamin A. Indian Pediatr 40, 585-587.

51. Swamy HM, Thakur JS, Bhatia SPS et al. (2002) Mass supplementation of vitamin A linked to national immunization day. Indian J Pediatr 69, 675-678.

52. Swamy HM, Thakur JS \& Bhatia SPS (2007) Impact of mass supplementation of vitamin A. Indian J Pediatr $\mathbf{7 4}$, 443-447.

53. Vijayarghavan K (2002) Control of micronutrient deficiencies in India: obstacles and strategies. Nutr Rev 60, 5 Pt 2, S73-S76.

54. Osei AK, Rosenberg IH \& Houser RF (2010) Communitylevel micronutrient fortification of school lunch meals improved vitamin A, folate, and iron status of schoolchildren in Himalayan villages of India. J Nutr 140, 1146-1154. 